\title{
Interactions Between the Space Experiments with Particle Accelerators Plasma Contactor and the Ionosphere
}

\author{
I. Katz* \\ Maxwell Laboratories, Inc., San Diego, California 92121 \\ J. N. Barfield, $\uparrow$ J. L. Burch, $\ddagger$ J. A. Marshall, $\S$ and W. C. Gibsond \\ Southwest Research Institute, San Antonio, Texas 78284 \\ T. Neubert** \\ University of Michigan, Ann Arbor, Michigan 48109 \\ W. T. Roberts †† \\ NASA Marshall Space Flight Center, Alabama 35812 \\ W. W. L. Taylor $+\div$ \\ Nichols Research Corporation, Arlington, Virginia 22209 \\ and \\ J. R. Beattie $\S$ \\ Hughes Research Laboratories, Malibu, California 90265
}

\begin{abstract}
Space experiments with particle accelerators (SEPAC) on Atlas-1 space transportation system (STS45) included a plasma contactor to neutralize charge buildup on the orbiter due to electron accelerator operations. The SEPAC plasma contactor operated the same as it had during testing in the laboratory. During SEPAC electron accelerator operations, the contactor emitted currents that helped balance the electron beam current. The Langmuir probe measured the charge exchange ions and the thermal electrons emitted by the contactor. The electric field wave data showed an order of magnitude increase in the 4-8 MHz band. There were no reports of contactor operations interfering with either orbiter systems or other Atlas-1 experiments.
\end{abstract}

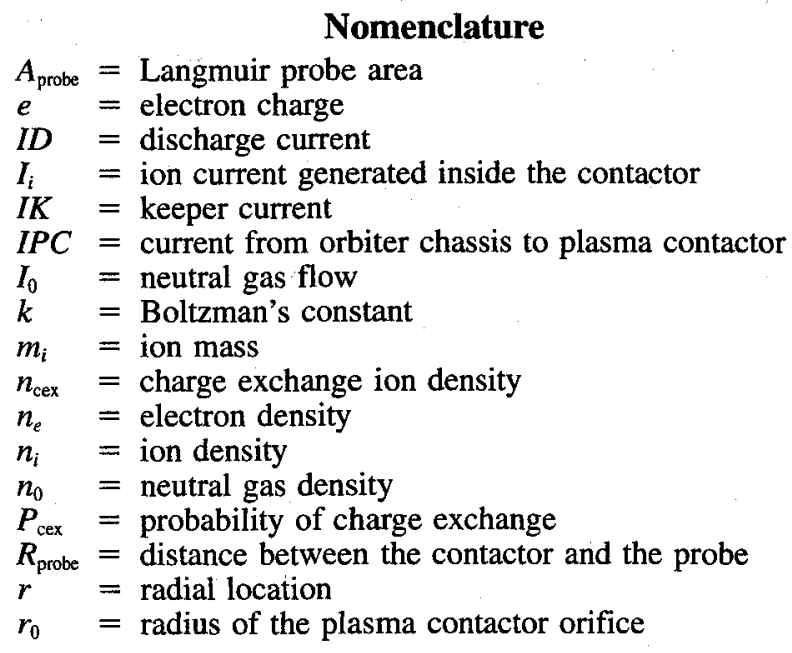

Received Jan. 15, 1993; revision received June 8, 1993; accepted for publication Aug. 18, 1993. Copyright (C) 1993 by the American Institute of Aeronautics and Astronautics, Inc. All rights reserved.

*Vice President; Manager, Space Systems Sector, S-Cubed Division, 3398 Carmel Mountain Road.

$\dagger$ Assistant Director. Member AIAA.

$¥$ †ice President.

§Manager, Sensor Design and Calibration.

TDirector, Department of Space Systems, Division of Instrumentation and Space Research, P.O. Drawer 2510. Member AIAA.

**Associate Research Scientist, Space Physics Research Laboratory, 2455 Hayward St.

$\dagger+$ Space Scientist, Payload and Orbital Systems Office.

$\ddagger$ Director of Space Sciences, NASA Programs, 1700 North Moore

Street, Suite 1820. Associate Fellow AIAA.

§Manager, Plasma Sources Department, Mail Stop RL-57, 3011

Malibu Canyon Road. Senior Member AIAA.

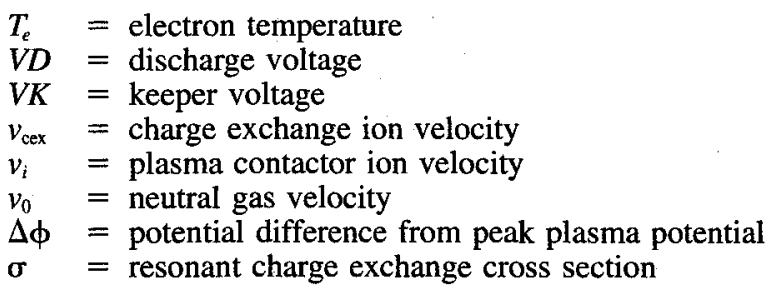

\section{Introduction}

Q PACE experiments with particle accelerators (SEPAC) on Atlas- $1^{1}$ included a plasma contactor to neutralize charge buildup on the orbiter due to electron accelerator operations. During the previous mission (Spacelab 1), at high power levels the SEPAC electron beam returned to the cargo bay causing intense optical emissions. ${ }^{2-4}$ The beam returned because the orbiter was unable to collect sufficient electrons from the ionosphere to balance those emitted by the beam. For the reflight on the space transportation system STS-45 Atlas-1 mission, SEPAC employed three different types of hardware to balance the beam current: three conducting spheres, a neutral gas release system, and a xenon plasma contactor. This paper focuses on the operation of the plasma contactor, which was used for the first time to neutralize an intense electron beam during a spaceflight. SEPAC hardware included diagnostic instrumentation, which was primarily intended to measure phenomena associated with electron beam interactions with the ionosphere but also provided useful data about the plasma generated by the plasma contactor, its interaction with the ionosphere, and its ability to control orbiter charging.

\section{Background}

Emission of charge neutral plasmas effectively controls spacecraft charging in geosynchronous orbit. Investigations on 
ATS $-6^{5,6}$ and SCATHA ${ }^{7}$ showed that emission of neutral plasma was more effective in balancing electron currents from the magnetosphere than the emission of electrons alone. Less than a milliampere is needed to control geosynchronous spacecraft charging. In low-Earth orbit, space electric rocket test II (SERTII) controlled spacecraft potentials over an $80-\mathrm{V}$ range by biasing hollow cathode plasma neutralizers. ${ }^{8.9}$ To neutralize the electron beam accelerator (EBA), the first SEPAC flight used a magnetoplasma dynamic (MPD) arcjet. The arcjet generated $\sim 10^{19}$ ion-electron pairs during a millisecond pulse that could be repeated every $15 \mathrm{~s}$. The resultant plasma dispersed within $100 \mathrm{~ms}$, too short a time to neutralize the orbiter during most of the electron beam operations. ${ }^{2-4}$ For the STS-45 mission, instead of the MPD thruster, a plasma contactor was added to SEPAC to provide steady-state charge and current neutralization. Figure 1 shows the configuration of the SEPAC experiment as flown on STS 45. In particular, notice the relative location of the plasma contactor with respect to the diagnostics package.

A plasma contactor is a discharge chamber where an expellant gas (xenon for SEPAC) is partially ionized by electron bombardment. The resultant dense, low temperature plasma expands into the surrounding space, driven by the quasineutral electric fields associated with density gradients. Following earlier work on plasma expansion into vacuum, ${ }^{10,11}$ we assume streaming ions and thermal electrons. ${ }^{12-14}$ The electrons that exit the discharge chamber are immediately thermalized, generating turbulence. The ions expand roughly hemispherically from the contactor orifice. The electron population is predominately Maxwellian; that is, the electron density depends exponentially on the potential divided by the electron temperature.

$$
\begin{aligned}
& n_{i}=I_{i} / 2 \pi r^{2} v_{i} e \\
& n_{e} \approx n_{i} \\
& n_{e} \approx n_{r=r_{0}} \exp \left(e \Delta \phi / k T_{e}\right)
\end{aligned}
$$

Laboratory data shows that the potential of the initial, unexpanded plasma is usually within a few volts of the bombardment chamber anode potential. ${ }^{15}$

Contactor plasma electrons are two orders of magnitude more mobile than the ions and normally carry most of the electrical currents. The expanding contactor plasma is only weakly collisional and can support electrical currents on the order of the thermal electron current. Only small changes in the potentials from those determined by quasineutral plasma expansion are needed to drive significant electron currents. ${ }^{12}$
External to the discharge chamber, the unused neutral expellant interacts strongly with the expanding plasma through resonant charge exchange. Cross sections for resonant charge exchange $\sigma$ approach $100 \AA^{2}$ for xenon. ${ }^{16}$ During charge exchange, slow moving thermal neutral atoms lose an electron to streaming ions. Because of their small velocities, the charge exchange ions respond strongly to density gradient electric fields and expand more nearly isotropically than the forwardstreaming contactor ions. Although only a small fraction of contactor ions, the charge exchange ions dominate the plasma density behind the orifice plane..$^{17}$ The characteristics of charge exchange plasmas external to an ion thruster have been studied in the laboratory ${ }^{17,18}$ and modeled numerically. ${ }^{19-21}$

\section{Space Experiments with Particle Accelerators Plasma Contactor}

The SEPAC plasma contactor ${ }^{22}$ generates about $2 \mathrm{~A}$ of singly charged xenon ions in a $25-\mathrm{cm}$-diam discharge chamber. The contactor, built by Hughes Research, is essentially a Kaufman thruster without ion accelerating electrodes. The contactor, as shown schematically in Fig. 2, has separate power supplies for the keeper and main discharge electrodes. The gas is ionized in a two-step process. A small amount, 0.7 standard cubic centimeter per minute $(\mathrm{sccm})$ of xenon gas, flows through the hollow cathode, through the hole in the keeper electrode, and into the main discharge chamber. Typically, the keeper discharge operated at $1.5 \mathrm{~A}(I K)$ and $17 \mathrm{~V}(V K)$. The keeper discharge provides seed ionization and acts as a low impedance cathode which supplies ionizing electrons to the main discharge chamber. Xenon gas flows directly into the main discharge chamber at a rate of $36.7 \mathrm{sccm}$. Small magnets in the discharge chamber enhance the ionization process. When operating at $7 \mathrm{~A}(I D)$, $36 \mathrm{~V}(V D)$ in the main discharge chamber, the plasma contactor ionizes about $75 \%$ of the total neutral xenon gas flow (37.4 sccm) generating $2 \mathrm{~A}$ of $\mathrm{Xe}$ ions and an equal quantity of electrons. Since the ionization takes place inside the discharge chamber, ambient plasma conditions do not affect the ionization. The dense, $n_{e} \approx 10^{17} \mathrm{~m}^{-3}$, cool, $T_{e} \approx 2 \mathrm{eV}$, plasma expands quasineutrally into the much less dense, colder surrounding ionosphere.

Because of the large ion current generated by the SEPAC plasma contactor, it could not be determined during the flight whether electrons were indeed the dominant current carriers. The SEPAC contactor was designed to support much larger electron currents than the EBA current; the contactor ion generation rate alone was larger than the maximum EBA current.

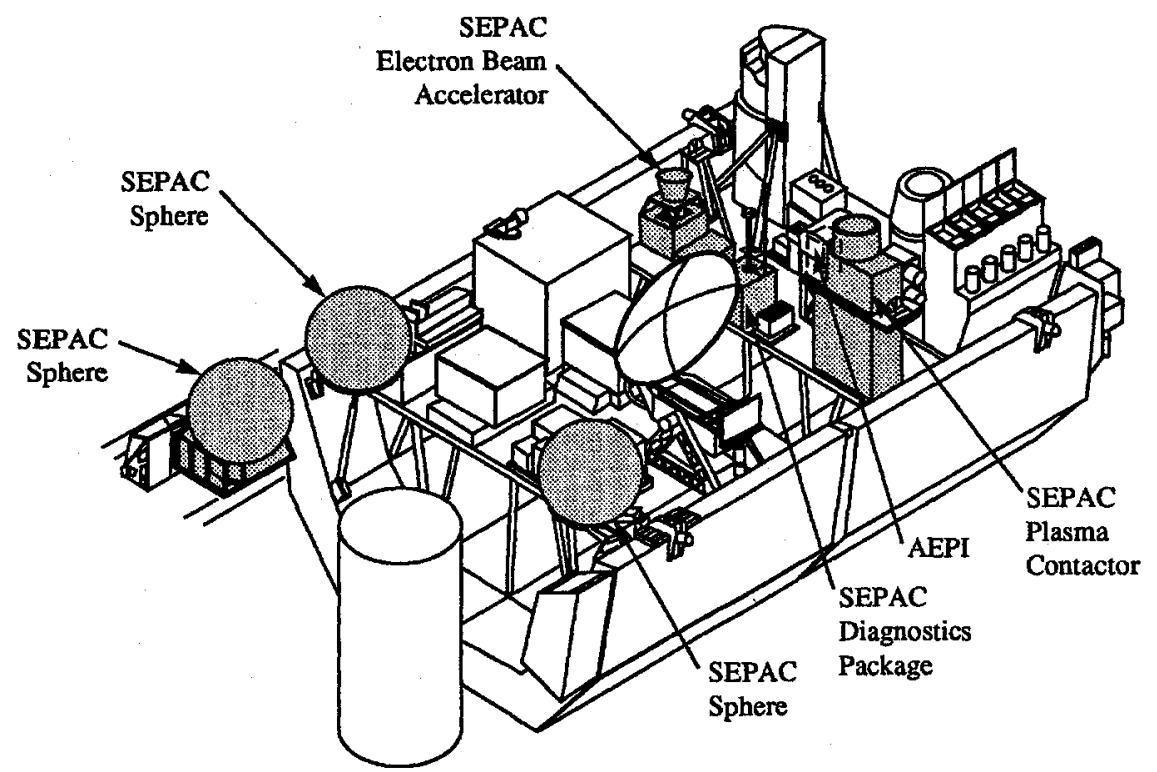

Fig. 1 Configuration of the SEPAC experiment as flown on STS 45. 


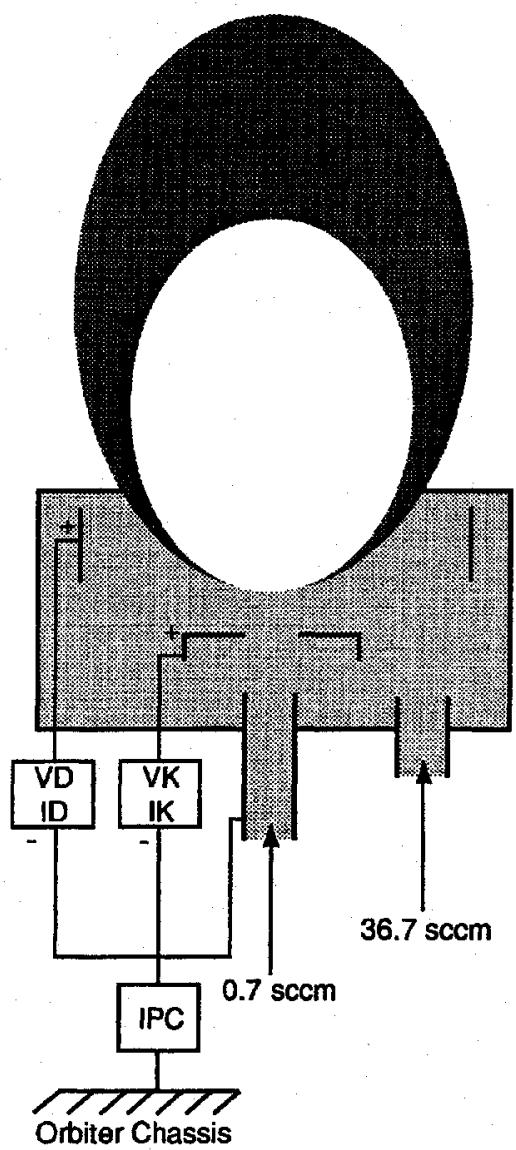

Fig. 2 Schematic of the SEPAC plasma contactor.

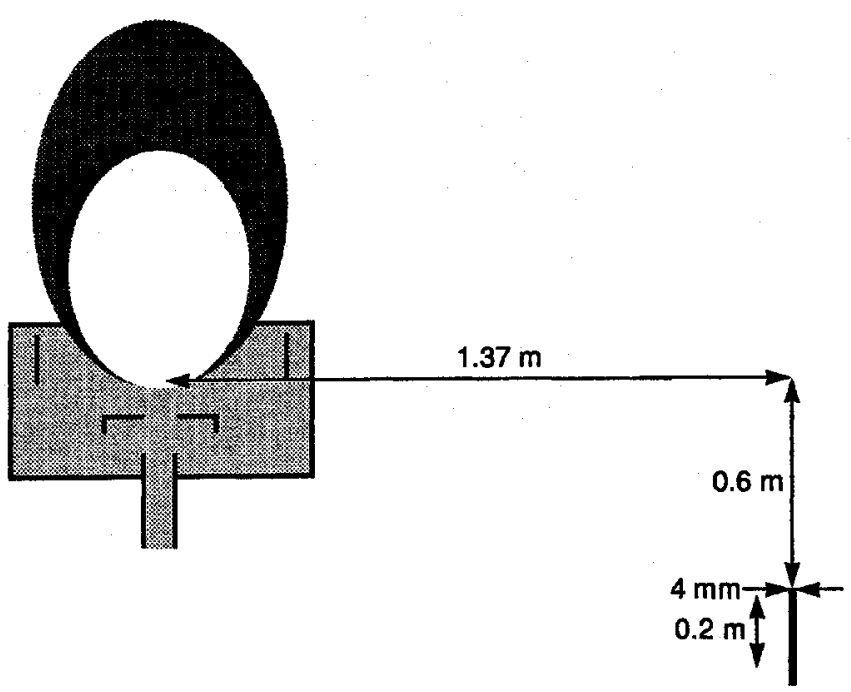

Fig. 3 Relative placement of the plasma contactor and the Langmuir probe in the Shuttle orbiter cargo bay.

The plenum gas pressure, the current and voltages in both power supplies, and the electron current flowing from the contactor to the orbiter chassis were monitored during the flight. Unfortunately, the current from the orbiter to the contactor (IPC) was monitored only when it was positive, so no information about plasma contactor electron emission was obtained.

The SEPAC plasma diagnostics package included a cylindrical Langmuir probe located, as indicated in Fig. 3, $1.37 \mathrm{~m}$ toward the center of the orbiter cargo bay and $0.6 \mathrm{~m}$ below the contactor orifice. The 4-mm-diam, 20-cm-long probe was swept $\pm 9 \mathrm{~V}$. As was seen in the first flight, the probe positive sweep voltage was not enough to observe electron current saturation due to the orbiter negative floating potential.
The SEPAC plasma instruments were located to the side and behind the contactor orifice and, consequently, measured primarily properties of the secondary, charge exchange plasma, as opposed to plasma ions generated inside the discharge chamber.

\section{Flight Results}

Atlas-1 was launched on March 24, 1992 aboard the orbiter Atlantis mission STS-45 in a $300-\mathrm{km}$ altitude, 57-deg inclination orbit. During the week-long mission, SEPAC performed 27 separate experiments using the plasma contactor, covering most orientations with respect to the Earth's magnetic field and orbiter velocity vectors, during both day and night, and near the Jicamarca radar observatory. For each of the 27 experiments, the contactor was restarted and operated flawlessly for a total of $7.3 \mathrm{~h}$, until the supply of xenon gas was depleted. The plasma contactor electrical data was the same as observed during laboratory testing. Consistently stable voltages and currents were seen in both the keeper and discharge circuits throughout the flight. All cathode starts occurred within a second of keeper voltage turn on; no high impedance modes were observed. Postflight examination confirmed the telemetry; all contactor circuits were nominal, and the xenon tank was empty. Most of the gas had been expended during SEPAC neutral gas release experiments. The plasma cloud was observed from Jicamarca. In the observation of the near cloud, it had a scattering cross section of about $20 \mathrm{~dB}$ larger than that of the orbiter. ${ }^{23}$

\section{Langmuir Probe}

Compared with the ambient ionosphere, during contactor operation the Langmuir probe showed a hotter, order-of-magnitude denser plasma. As can be seen in Fig. 4, the Langmuir probe traces were noisy both with the contactor on and off. These measurements were made when the beam was off and the orbiter was in the Earth's shadow. Figure 4 shows probe currents when the contactor was in the wake of the Shuttle and when the contactor was in the ram. Although electron current saturation was not observed, enough of the electron trace is available to fit a temperature. The ion current collected is determined from a least squares fit of points with negative voltages; the electron temperature was determined from a fit to the points from 1.80 to $5.96 \mathrm{~V}$ for the wake case, from 3.8 to $8 \mathrm{~V}$ for the ram case, and from 7.9 to $9.5 \mathrm{~V}$ for the ram case with the contactor off. For the cases examined, the electron current fit an exponential fairly well, with an electron temperature between 1.5 and $2.1 \mathrm{eV}$. As Table 1 shows, the highest temperatures occurred when the contactor was in the wake. Closer interaction with the cooler ionosphere may lower the contactor plasma electron temperature.

Because the Langmuir probe was behind the main contactor orifice, it presumably measured the secondary ions generated by charge exchange occurring in front of the orifice between the main plume and un-ionized xenon. We can test this hypothesis by comparing the measured ion currents with ion currents expected from charge exchange.

Assuming the neutral xenon emanating from the orifice expands into a $\pi$ solid angle,

$$
n_{0}(r) \approx \frac{I_{0}}{e \pi r^{2} v_{0}}
$$

As long as the neutral gas is not depleted, the probability of charge exchange $P_{\text {cex }}$ external to the contactor is

$$
P_{\text {cex }}=\int_{r_{0}}^{\infty} n_{0}(r) \sigma \mathrm{d} r \approx \frac{I_{0} \sigma}{e \pi r_{0} v_{0}}
$$

The median distance from the orifice for charge exchange is $2 r_{0}$. Assuming that the charge exchange ion expansion is spheri- 
Table 1 Electron temperatures and ion currents during plasma contactor operation

\begin{tabular}{lccc}
\hline Time GMT & Orientation & $T_{e}, \mathrm{eV}$ & Ion current, $\mu \mathrm{A}$ \\
\hline $87 / 01: 15: 18$ & Ram & 1.5 & 2.1 \\
$88 / 01: 14: 10$ & Wake & 2.1 & 0.6 \\
$89 / 11: 51: 46$ & Down & 1.9 & 2.2 \\
$90 / 18: 50: 5$ & Down & 1.2 & 3.1 \\
\hline
\end{tabular}

87/01:13:18 Ram, Contactor Off

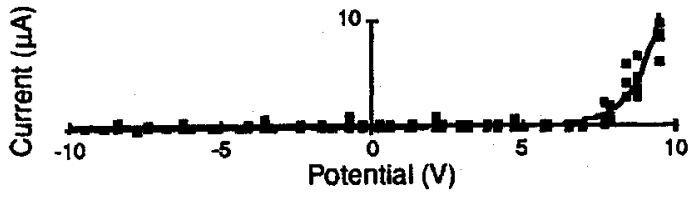

87/01:15:18 Ram, Contactor On

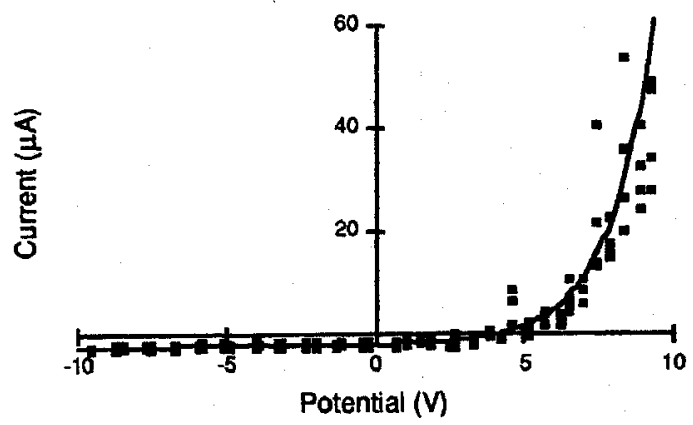

88/01:13:50 Wake, Contactor Off

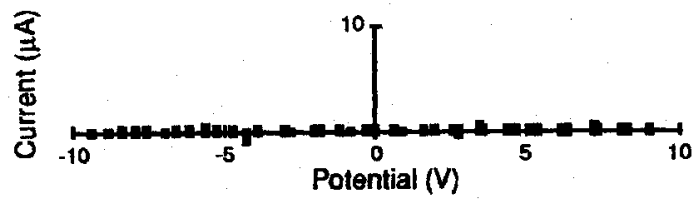

88/01:14:10 Wake, Contactor On

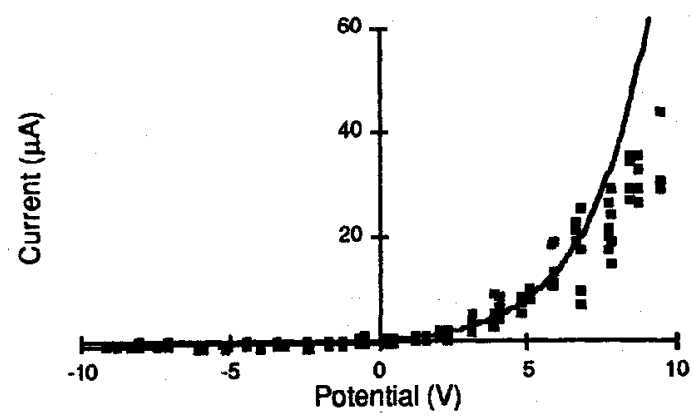

Fig. 4 Langmuir probe currents.

cal, and noting that the distance to the probe is large compared with the orifice size, we can estimate the current to the Langmuir probe,

$$
I_{\text {probe }} \approx \frac{A_{\text {probe }}}{4 \pi R_{\text {probe }}^{2}} P_{\text {cex }} I_{i}
$$

The probe area used is the cross section to streaming flow, $8 \times 10^{-4} \mathrm{~m}^{2}$. Taking the neutral gas velocity to be $300 \mathrm{~m} / \mathrm{s}$, the probability of charge exchange ranges from $7 \%$ if the contactor ionizes $50 \%$ of the xenon, down to $3 \%$ if the contactor ionizes
$80 \%$ of the xenon. During laboratory operation, this was the range of expellant utilization observed. With the flight parameters expellant utilization in the laboratory was $75 \%$. The predicted range of probe currents due to charge exchange is 1.7-2.7 $\mu \mathrm{A}$. The observed saturation ion currents extrapolated to zero potential range between 1.9 and $3.1 \mu \mathrm{A}$, consistent with this simple picture.

The charge exchange ion density $n_{\text {cex }}$ is approximately

$$
n_{\mathrm{cex}} \approx \frac{P_{\mathrm{cex}} I_{i}}{e 4 \pi r^{2} v_{\mathrm{cex}}}
$$

Because the Shuttle floats negative, the potential difference between the discharge chamber anode and the local environment is less than the $36-V$ discharge potential. This potential provides an upper bound on the charge exchange ion velocity, 7300 $\mathrm{m} / \mathrm{s}$. For a charge exchange current of $2 \mu \mathrm{A}$, the charge exchange plasma density at the probe would be at least $2 \times 10^{12} \mathrm{~m}^{-3}$. This density is also consistent with the Langmuir probe not showing electron saturation. The corresponding electron saturation current is about $200 \mu \mathrm{A}$, far in excess of $112 \mu \mathrm{A}$, the maximum current that the probe was capable of measuring. The voltage sweep also limited the probe's operation. From the analyzed data it appears that the saturation current would occur at about 10-V positive, which is above the upper end of the probe voltage sweep range.

\section{Charge Control During Electron Beam Accelerator Operations}

During joint EBA and plasma contactor operations, the contactor current neutralized a portion of the EBA electron current. Data shows that for an EBA emission current greater than $100 \mathrm{~mA}$, current flowed between the contactor and the orbiter chassis. Figure 5 shows an example in which the EBA current reached $0.8 \mathrm{~A}$. These measurements were made in the Earth's shadow with the bay facing up. The figure shows the electron beam voltage (top) in volts, the electron beam current (middle) in amperes, and the current from the orbiter chassis to the plasma contactor (bottom) in amperes. The variation in the beam was preprogrammed. In this case the plasma contactor accounted for more than half of the return current. The contactor current was consistently less than the EBA current. This is consistent with preflight expectations that the orbiter exposed conducting surface would collect thermal electron current and the contactor would make up the difference to keep the orbiter from charging. Since the orbiter did not charge, the beam escaped even at the highest currents. During the flight, the electron beam generated artificial aurora in the upper atmosphere more than $100 \mathrm{~km}$ from the orbiter.'

At maximum EBA electron current, $850 \mathrm{~mA}$, the plasma contactor emitted $650 \mathrm{~mA}$. Because the contactor generated 2 $A$ of ions, it is unclear from the data whether the contactor

86/2:20:46, Bay Up

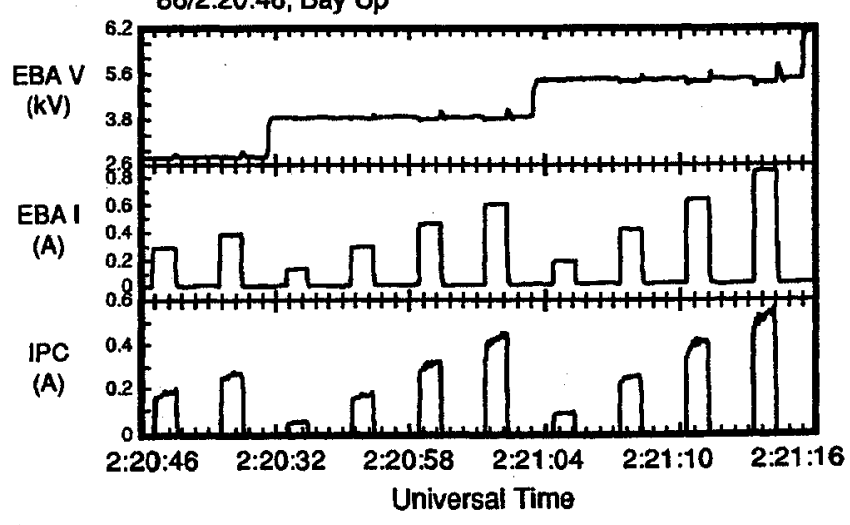

Fig. 5 Flight data showing current collected by the plasma contactor during SEPAC electron beam accelerator operation. 
current was carried by electrons flowing in from the ionosphere or by ions flowing from the contactor out to the ionosphere. The ambient environment had no effect on plasma contactor operation, since the plasma produced by the contactor overwhelmed the background plasma in the vicinity of the Shuttle. Contrary to some expectations, there were no observations of any visible beam plasma discharges during plasma contactor operations.

Every time the contactor discharge was started, a current spike of the order of $100 \mathrm{~mA}$ of current was emitted for a few tenths of a second. Figure 6 shows the plasma contactor emitting current after turn on, with neither neutral gas nor EBA emission. These measurements were made in the Earth's shadow with the bay facing down. The bottom two curves are the Langmuir probe potential in volts and the current in microamperes. The middle curve is the current from the orbiter chassis to the plasma contactor in amperes. The top two curves are from the wave detectors. The figure shows a current spike of $70 \mathrm{~mA}$ at contactor turn on. Although probably associated with differential charging of nearby orbiter surfaces, no quantitative model of this unanticipated emission has been developed.

The contactor currents during SEPAC neutral gas release experiments are not understood. During EBA operation, the neutral gas release occurred just prior to the electron beam turn on. Figure 7 shows typical behavior of the plasma contactor current during a neutral gas release. These measurements were made in the Earth's shadow with the bay facing up. The bottom

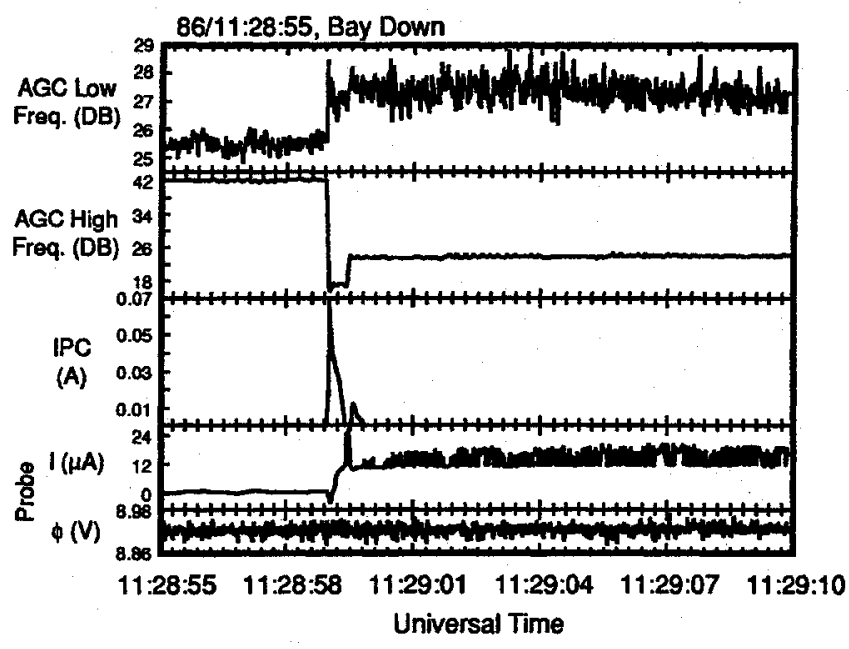

Fig. 6 Plasma contactor emitting current after turn on, with neither neutral gas nor EBA emission, also electric field wave data measured during SEPAC plasma contactor operation.

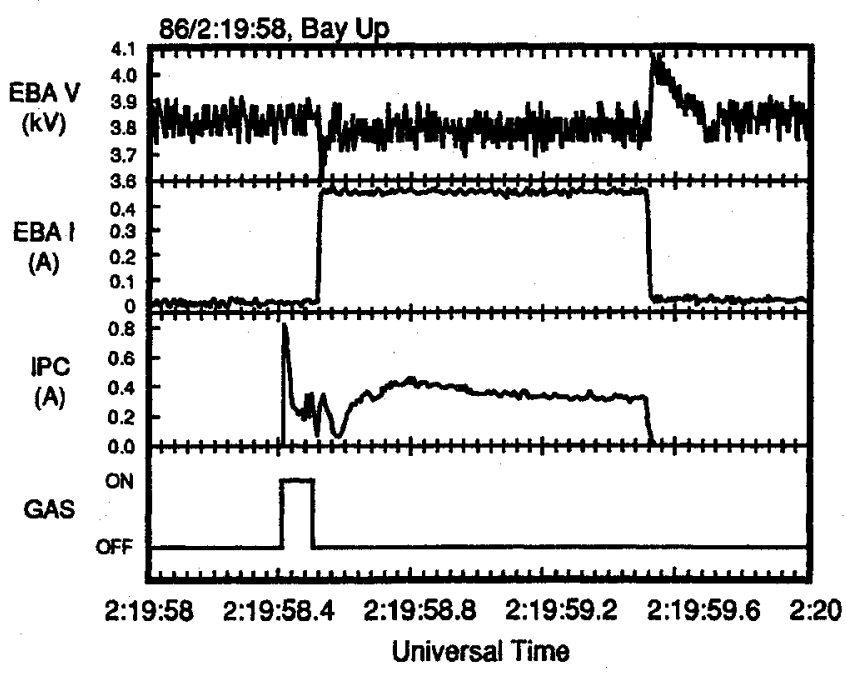

Fig. 7 Plasma contactor current during neutral gas release. curve shows the neutral gas release. The next curve shows the current from the orbiter chassis to the contactor in amperes. The top two curves are the electron beam potential in volts and the current in amperes. Note that the potential variation is shown on an expanded scale. The plasma contactor current shows an ampere level surge during the gas release, followed by a rapid decay until beam turn on. The source of these electrons and the current closure path are not presently known. When the electron beam is turned on, the contactor current slowly rises to a value greater than without neutral gas and then decays slowly.

\section{Field Fluctuations}

The diagnostics package included a wave receiver connected to a half-meter electric field antenna. Both narrow-band and broadband signals were measured. The broadband receiver measured the gain necessary to output a $1-V$ signal in three frequency ranges. The antennas were located adjacent to the Langmuir probe. The automatic gain control (AGC) high signal is for the 4-8 MHz band. The AGC low signal is for the 400 $\mathrm{Hz}-10 \mathrm{KHz}$ band and comes from a Faraday cup mounted atop the high frequency antenna. The operation of the plasma contactor had the greatest effect in the $4-8 \mathrm{MHz}$ band, the highest frequency measured. Increases of greater than $20 \mathrm{~dB}$ were observed in the electric field energy compared with the ambient plasma. During some contactor operations, when the cargo bay was in the ram, the wave intensity was sufficient to saturate the receiver, corresponding to fluctuating fields of approximately $1 \mathrm{~V} / \mathrm{m}$. When the cargo bay was not in the ram, the intensity of the fluctuating fields was lower, the order of $0.1 \mathrm{~V} / \mathrm{m}$. Figure 6 shows electric field wave data measured during SEPAC plasma contactor operation. The top two curves are the AGC low and AGC high data. The data shown indicates oscillating electric fields of order $0.1 \mathrm{~V} / \mathrm{m}$. During this period the Langmuir probe was held at a constant potential to measure the density fluctuations. The noisy current reflects the variation in the density. The plasma contactor electromagnetic radiation did not interfere with orbiter systems.

Intense electrostatic fluctuations in the contactor plasma are consistent with the Langmuir probe current fluctuations observed when the probe bias voltage was fixed. Published models of hollow cathode plasma contactors predict large amplitude electrostatic turbulence as a result of electrons streaming from the cathode into the contactor plasma. 12,24 The cathode electrons are accelerated by the discharge potential and form an unstable beam in the local dense plasma. These streaming electrons ionize the contactor gas, generating the contactor plasma. The beam also generates intense electrostatic waves which scatter and thermalize part of the beam. Not presently understood is how the electrostatic turbulence decays.

\section{Summary}

During the Atlas-1 mission (STS-45), the SEPAC plasma contactor operated the same as it had during testing in the laboratory. Although there were no measurements in the contactor plume, the charge exchange plasma behind the contactor dominated Langmuir probe currents and was consistent with previous, ground-based measurements. During SEPAC electron accelerator operations the contactor emitted currents that helped balance the electron beam current. There was no evidence of charging, electron beam return, or beam plasma interactions during plasma contactor operations. Highest electron temperatures were observed during deep wake operations, suggesting that thermal conduction with the ionosphere tended to cool the expanding contactor plasma. During plasma contactor operations the electric field wave data showed an order of magnitude increase in the $4-8-\mathrm{MHz}$ band. There were no reports of contactor operations interfering with either orbiter systems or other Atlas-1 experiments.

\section{Acknowledgments}

This work was supported by NASA Contracts NAS8-32488 and NAS8-38772. The authors gratefully acknowledge the work 
of the entire SEPAC team and the Atlas-1 POCC cadre and crew. Ira Katz would like to thank the Space Station Freedom Program for enabling his participation in SEPAC and V. A. Davis for help in preparation of this paper.

\section{References}

'Burch, J. L., Mende, S. B., Kawashima, N., Roberts, W. T., Taylor, W. W. L., Neubert, T., Gibson, W. C., Marshall, J. A., and Swenson, G. R., "Artificial Auroras in the Upper Atmosphere 1. Electron Beam Injections," Geophysical Research Letters, Vol. 20, No. 6, 1993, pp. 491-494.

${ }^{2}$ Sasaki, S., Journal of Spacecraft and Rockets, Vol. 23, No. 2, 1986, p. 194.

${ }^{3}$ Obayashi, et al., Science, Vol. 225, No. 195, 1984.

${ }^{4}$ Sasaki, S., et al., Geophys. Res. Letters, Vol. 12, No. 10, 1985, pp. $647-650$.

${ }^{5}$ Olsen, R. C., "Experiments in Charge Control at Geosynchronous Orbit-ATS-5 and ATS-6," Journal of Spacecraft and Rockets, Vol. 22,1985 , pp. 254-264.

${ }^{6}$ Purvis, C. K., Bartlett, R. O., and DeForest, S. E., "Active Control of Spacecraft Charging on ATS-5 and ATS-6," Proceedings of the Spacecraft Charging Technology Conference, edited by C. P. Pike and R. R. Lovell, 1977, pp. 107-120.

${ }^{7}$ Cohen, H. A., et al., "P78-2 Satellite and Payload Responses to Electron Beam Operations on March 30, 1979," Spacecraft Charging Technology, 1980; also NASA CP 2182, AFGL-TR-81-0270, 1981, pp. 509-559.

${ }^{8}$ Kerslake, W., and Domitz, S., "Neutralization Tests on the SERT II Spacecraft," AIAA Paper 79-2064, 1979.

9 Jones, S. G., Staskus, J. V., and Byers, D. C., "Preliminary Results of SERT II Spacecraft Potential Measurements Using Hot Wire Emissive Probes," AIAA Paper 70-1.127, 1970; also NASA TM X-2083, 1970.

${ }^{10}$ Crow, J. E., Auer, P. J., and Allen, J. E., Journal of Plasma Physics, Vol. 14, No. 65, 1975.

"Gurevich, A. V., Pitaevskii, L. P., and Smimova, V. V., "Ionospheric Aerodynamics," Space Science Review, Vol. 9, No. 805, 1969.

${ }^{12}$ Davis, V. A., Katz, I., Mandell, M. J., and Parks, D. E., "Hollow Cathodes as Electron Emitting Plasma Contactors: Theory and Computer Modeling," Journal of Spacecraft and Rockets, Vol. 25, No. 2, 1988 , pp. $175-179$.
${ }^{13}$ Parks, D. E., Katz; I., Buchholtz, B., and Wilbur, P., "Expansion and Electron Emission Characteristics of a Hollow Plasma Contactor," Journal of Applied Physics, (submitted for publication, April, 1993).

${ }^{14}$ Williams, J. D., and Wilbur, P. J., "Electron Emission from a Hollow Cathode-Based Plasma Contactor," Journal of Spacecraft and Rockets, Vol. 29, No. 6, 1992, pp. 820-829.

${ }^{15}$ Hayakawa, Y., Miyazaki, K., and Kitamura, S., "Measurements of Electron Energy Distributions in a $14 \mathrm{~cm}$ Diameter Ring Cusp Ion Thruster," AIAA Paper 89-2715, 1989.

${ }^{16}$ Rapp, D., and Francis, W. E., "Charge Exchange between Gaseous Ions and Atoms," Journal of Chemical Physics, Vol. 37, No. 11, 1961, p. 2631.

${ }^{17}$ Kaufman, H. R., "Charge-Exchange Plasma Generated by an Ion Thruster," NASA CR-135318, 1977.

${ }^{18}$ Carruth, M. R., and Brady, M. E., "Propagation of ChargeExchange Plasma Produced by an Ion Thruster," AIAA Paper 80$1388,1980$.

${ }^{19}$ Katz, I., Parks, D. E., Mandell, M. J., and Schnuelle, G. W., "Parasitic Current Losses Due to Solar-Electric Propulsion Generated Plasma," Journal of Spacecraft and Rockets, Vol. 19, No. 2, 1981, pp. 129-132.

${ }^{20}$ Carruth, M. R., Jr., and Pawlik, E. V., "Interactions Between a Spacecraft and an Ion Thruster Produced Environment," AIAA Paper 79-2107, 1979.

${ }^{21}$ Staggs, J. F., Gula, W. P., and Kerslake, W. R., "Distribution of Neutral Atoms and Charge-Exchange Ions Downstream of an Ion Thruster," Journal of Spacecraft and Rockets, Vol. 5, No. 2, 1968, pp. 159-164.

${ }^{22}$ Beattie, J. R., Marshall, J. A., Burch, J. L., and Gibson, W. C., "Design, Qualification, and On-Orbit Performance of the ATLAS Plasma Contactor," AIAA Paper, 1993 Electric Propulsion Conference.

${ }^{23}$ Jost, R. J., Neubert, T., Farley, D. T., Rodriguez, R., Calderon, C., Woodman, R., and Burch, J. L., "Radar Observations of ATLAS-1 Plasma Contactor Disturbances from Jicamarca Observatory," EOS, Geophysical Society Journal, Vol. 73, No. 43, Supplement, 1992, p. 412 .

${ }^{24}$ Hastings, D. E., "Enhanced Current Flow Through a Plasma Cloud by Induction of Plasma Turbulence," Journal of Geophysical Research, Vol. 92, No. A7, 1987, pp. 7716-7722.

Alfred L. Vampola Associate Editor 